University of Nebraska - Lincoln

DigitalCommons@University of Nebraska - Lincoln

Faculty Publications: Department of Teaching, Department of Teaching, Learning and Teacher Learning and Teacher Education

2016

Being "in a Limbo": Perceptions of Immigration, Identity and Adaptation of Immigrant Students in South Africa and the United States

Theresa Catalano

Jill Fox

Saloshna Vandeyar

Follow this and additional works at: https://digitalcommons.unl.edu/teachlearnfacpub

Part of the Curriculum and Instruction Commons, and the Teacher Education and Professional Development Commons

This Article is brought to you for free and open access by the Department of Teaching, Learning and Teacher Education at DigitalCommons@University of Nebraska - Lincoln. It has been accepted for inclusion in Faculty Publications: Department of Teaching, Learning and Teacher Education by an authorized administrator of DigitalCommons@University of Nebraska - Lincoln. 


\title{
Being "in a Limbo": Perceptions of Immigration, Identity and Adaptation of Immigrant Students in South Africa and the United States
}

\author{
Theresa Catalano, ${ }^{1}$ Jill Fox, ${ }^{1}$ and Saloshna Vandeyar ${ }^{2}$ \\ 1 University of Nebraska-Lincoln \\ 2 University of Pretoria \\ Correspondence - Theresa Catalano tcatalano2@unl.edu Department of Teaching, \\ Learning and Teacher Education, 27 Henzlik Hall, University of Nebraska-Lincoln, \\ 1430 Vine Street, Lincoln, NE 68588.
}

\begin{abstract}
Much research is available that details student experiences of immigration and adaptation to receiving countries and schools, but few studies analyze the metaphors used by immigrant students (IS) when talking about the immigration experience, or offer a comparative lens through which to view identity negotiation in two very different contexts. The present paper aims to address these gaps by conducting a comparative linguistic analysis of 20 interviews conducted with IS at universities in South Africa and the United States in order to gain a greater understanding of immigration and the types of identity negotiation processes learners undergo in these very different countries. Findings reveal interesting similarities between metaphorical conceptions of immigration across different cultural contexts and a remarkable resilience in the use of adaptation strategies and identity development that leads to salient pedagogical implications for teachers of higher education who face increasingly international classrooms.
\end{abstract}

Keywords: applied linguistics, comparative international education, higher education, identity construction, immigration, metaphor analysis

Published in Journal of Language, Identity \& Education 15:3 (2016), pp 137-150.

doi:10.1080/15348458.2016.1165099

Copyright (C) 2016 Taylor \& Francis. Used by permission. 
Rosa Maria always dreamed of seeing the world. Born in Colombia, she obtained a bachelor's degree in industrial design and is currently a doctoral student in education. Rosa Maria believes that immigration is a great risk, but it is a risk she would be willing to take again, even though she often feels as if she is living "in a limbo"-part of her in Colombia, part in Spain, and part in the United States.

Malik believed that all his dreams would come true if he moved to the United States. He thought he would arrive at his destination to find a car, house, and job waiting for him. He describes Iraq as a "big prison" where his "future was black." Luckily, because of his work as a translator, U.S. forces helped Malik get a visa to come to the U.S. Midwest, where he is now a student at a local university. Malik loves his new country and believes there is a "formula" for being successful in his new life and that education is a big part of that formula.

Amadi moved to South Africa from Nigeria in search of "greener pastures" and to "build" his professional career. However, he was shocked upon his arrival to find the level of unemployment and poverty among Black South Africans even higher than in the country he "escaped from." With assistance from his family he enrolled in a master's program and took up odd jobs, such as being a security guard, computer technician, and Internet shop attendant. One of Amadi's memorable experiences included being arrested for not offering bribes to local police officers who later accused him of being a "fake" Nigerian since he did not succumb to their requests to pay. Over the duration of his stay in South Africa, Amadi has come to learn that as a "Nigerian carrying a South African passport. . . no matter how you try to be friendly and humane, you are perceived by the locals to be a threat." He often wonders, "Is it worth it?"

Maiba traveled from Cameroon to South Africa because she wanted a "quality education" that would improve her life and future. Although the experience has been stressful and "hectic," she is hoping to "sail through the odds" and finds her new life "much more fulfilling" because of her research. She does not regret coming to South Africa to study because through her new education she sees so many "opportunities opening up."

The above vignettes illustrate just a taste of the vast differences in types of experiences immigrant students undergo and the unique perceptions of migration that each individual has. Much research features 
the voices and stories of immigrant international students of various levels through narrative inquiry or case studies (e.g., Chan, 2004; Copland \& Garton, 2011; Guo \& Chase, 2011; Kim \& Egan, 2010; SuárezOrozco \& Suárez-Orozco, 1995, 2001; Williams \& Johnson, 2011), while others investigate the negotiation of identity throughout these experiences (Hsieh, 2006; Kim, 2009; Suárez-Orozco, 2000, 2004; Vandeyar, 2012; Wadsworth, Hecht, \& Jung, 2008). In addition, many studies describe and analyze metaphors of the immigration experience in media discourse (e.g., Cisneros, 2008; Hart, 2010; Santa Ana, 1999), but few studies analyze the metaphors used by immigrant students (IS), defined here as students who come to a new country and plan to stay there permanently, to talk about the immigration experience and the personal identity work involved. Furthermore, few studies compare and contrast what IS experience in two very different sociocultural, economic, political, and geographical contexts. The present paper addresses these gaps in the literature by conducting a comparative linguistic analysis of 20 interviews conducted in universities in South Africa and the United States with IS (mostly graduate students) who plan to stay in their countries of study. ${ }^{1}$ The aim of this comparative linguistic analysis is to gain a greater understanding of what immigration means for IS and the types of identity negotiation processes they undergo in these very different countries. Furthermore, by providing excerpts from the interviews, the authors hope to bring forward the individual voices of IS so that educators in higher education can understand how to better serve this growing global population. Finally, the authors will demonstrate the value of metaphor analysis in narrative inquiry as a "window into the mind" of immigrant students (Hart, 2011, p. 72).

\section{Theoretical framework}

\section{Communication identity theory}

While we do not pretend to cover all of the findings or types of identity delineated in identity-based research in this short summary, we hope to provide readers with information about IS identity most relevant to this study. Communication identity theory (CIT) provides a 
multilayered construct from which we can view identity (Wadsworth et al., 2008) and a basis for situating our linguistic analysis. Scholars of this theory (e.g., Hecht, Jackson, Lindsley, Strauss, \& Johnson, 2001; Hecht, Jackson, \& Ribeau, 2004; Hecht, Warren, Jung, \& Krieger, 2004) propose that identity is both a sense of self and a communication or an enactment of self and that there are 4 different frames of identity that "merge the individual with the society around him/her" (Wadsworth et al., 2008, p. 67). These frames are personal identity (in the sense of self-concept), enacted identity (how one expresses his/ her identity through communication with others), relational identity (which is co-created through roles and interactions with other people), and communal identity, (which is another way to say "ascribed identity," or how others in society view him/her).

According to this model, problems can occur when there are differences among these different frames (referred to as identity gaps). In Wadsworth et al.'s (2008) influential study, the authors found that the acculturation process (which we refer to as adjustment or adaptation) was found to be related to identity because as students adjust and adapt more to the receiving culture, their identities begin to encompass the new culture (Berry, 2003) and they communicate their identities well to others and others understand them better. On the other hand, when IS perceive discrimination against them (from the receiving culture's attitudes and behaviors toward them), this influences their behavior and relations with receiving culture members in a negative way because these students are not able to express themselves freely with receiving culture members (in the case of Wadsworth et al., 2008). Suárez-Orozco (2000) refers to this concept as the social mirror and Vandeyar (2012) notes that when the reflected image is generally positive, "the individual is able to feel that she is worthwhile and competent" (p. 3). When the reflection is generally negative, "it is extremely difficult to maintain an unblemished sense of self-worth" (p. 3).

For IS, one of the most problematic identity markers and means by which they feel discriminated against is language proficiency (Wadsworth et al., 2008). Research has shown that American undergraduates tend to perceive IS' and teachers' English proficiency to be a major barrier in classroom communication (Bresnahan \& Kim, 1993; Fitch \& Morgan, 2003; Rubin, 1992; Rubin \& Smith, 1990) and that 
international students are often acutely aware of these perceptions on the part of their receiving culture and classmates. These students then begin to perceive differences between their personal identity and the one ascribed to them by their receiving culture (such as "foreigner" or "outsider"), which then results in negative consequences in terms of relationships and communication with receiving culture members. Intercultural competence of IS can be an important factor in whether identity gaps occur. According to Kim (2009), IS that possess a strong identity security (the degree to which individuals feel secure about their identity) and inclusive identity (the cognitive refinement that allows people to perceive and orient themselves to dissimilar others and interact interculturally in a more sensitive way) have been found to engage in cooperative intercultural relationships more successfully.

In forming identities, the structural and attitudinal environment play a critical role (Suárez- Orozco \& Suárez-Orozco, 2001; Taylor, 1994). IS "must not only deal with aspects of personal development shared by all adolescents (relationships, work choices, examining values) but also often confront culture-related differences concerning these choices" (Vandeyar, 2012, p. 3). They must also attempt to create their identity through personal choices surrounding relationships, occupation, worldviews, and values that often conflict with parental and other family expectations (Dion, 2006; Murrell, 1999). How IS are received plays an important role in the adaptation/adjustment of these students (Suárez-Orozco \& Suárez-Orozco, 2001) and can be detrimental in their ability to participate in the opportunity structure (Taylor, 1994).

\section{Conceptual metaphor theory}

In order to provide a more nuanced and in-depth understanding of the identity negotiation process (as well as a greater understanding as to how IS experience immigration), we turn to conceptual metaphor theory. Conceptual metaphor theory is most familiar to the general public through the work of cognitive linguists George Lakoff and Mark Johnson (1980). While many readers might know of metaphor as a poetic device used in literature and poetry, we will define metaphor according to a cognitive linguistic (CL) ${ }^{2}$ frame as conceptual mappings from one semantic source domain (the more concrete and clearly organized 
domain) to a different semantic target domain (the more abstract and more difficult to talk about one; see Kövecses, 2006). An example relevant to this article is the metaphor IMMIGRATION IS WAR ${ }^{3}$ (note the use of small capital letters to denote metaphors, as per CL conventions). In this metaphorical comparison, the characteristics and qualities of war are mapped onto the process of immigration. Thus, in the discourse, one might find linguistic realizations of this conceptual metaphor (such as struggle, fight, frontlines, defend, weak position) that are used to talk about immigration by the participants. It is essential to understand that metaphor is not just a rhetorical device used consciously, but that metaphors "are pervasive in everyday life, not just in language but in thought and action" (Lakoff \& Johnson, 1980, p. 1) and this unconscious use of metaphor can be invaluable in understanding how people perceive of actions, events, and people.

Metonymy is another essential concept in CL that will be useful to examine identity negotiation of participants. Metonymy is a cognitive device similar to metaphor, but in contrast to metaphor, it can be defined as a mapping whereby a source provides access to a target because there is a perceived connection or association between the source and the target (Dirven, 2002; Jakobson, 1956). This target then becomes activated and foregrounded while the source is backgrounded (Benczes, 2011; Panther \& Thornburg, 2003). Metonymy can also be thought of as WHOLE FOR PART and PART FOR WHOLE relationships, referred to respectively as target-in-source and sourcein-target (Ruiz de Mendoza Ibáñez and Diez Velasco (2002). For example, in the sentence "She's taking the pill," pill stands for "contraceptive pill," which would make it a WHOLE FOR PART relationship because in this case, all pills are standing for a specific one. On the other hand, in the sentence "All hands on deck," hands stands for the sailors (PART FOR WHOLE) who do all the hard manual labor mostly with their hands, which are the most important parts (Ruiz de Mendoza Ibáñez \& Diez Velasco, 2002, p. 497). A good example of metonymy from our data would be Kwerekwere. This term is a derogatory metonymy of onomatopoeia given to foreigners who came to South African townships but could not speak local languages. Thus, the sound of their "babble" sounded like kwerekwere (this term came to stand first for the sound of languages other than local ones) and by second order meaning, foreigners or outsiders, specifically Black 
Africans from other countries. Hence there is a PART FOR WHOLE relationship in which the word Kwerekwere stands for the sound and the sound stands for the people making the sound.

Recent work in CL argues that metonymy, like metaphor, is a fundamental part of the conceptual system and shapes the way we think and speak of ordinary events (Gibbs, 1999). It can be used for drawing inferences and for reasoning about and understanding the world (Ruiz de Mendoza Ibáñez \& Perez Hernández, 2003) and is therefore a useful instrument in analyzing discourse regarding identity because metonymies are frequently used to refer to a person's identity (e.g., nationyms such as Italian, Chinese) or how others view IS.

\section{Method}

\section{Participants}

Participants for this study consisted of 10 IS from a medium-sized Midwestern university in the United States and 10 from a mediumsized university in South Africa. Eligibility criteria for inclusion in the study consisted of the following: (a) They must currently be a graduate or undergraduate student, (b) must be 19 or older, and (c) must have at least tentative plans to stay in the receiving country (United States or South Africa) on a permanent basis. Purposeful sampling criteria were met when participants confirmed that they were eligible (according to the above criteria) and available for interviews. Participants varied in terms of gender, countries of origin, and reasons for coming. Table 1 provides a brief profile of the participants and their reasons for migrating as well as their countries of origin. All participant names are pseudonyms.

\section{Data collection}

Participants in the United States were interviewed by the first and second author while interviews in South Africa were conducted by the third author and a graduate assistant. All interviews were conducted in September and October of 2013, in and around both campuses. The international review boards at both institutions approved participant 
Table 1. Participants.

\begin{tabular}{|c|c|c|c|c|}
\hline Participants & Gender & $\begin{array}{l}\text { Country } \\
\text { of origin }\end{array}$ & $\begin{array}{l}\text { Receiving } \\
\text { country }\end{array}$ & Reason for coming \\
\hline Ana & $\mathrm{F}$ & Chile & U.S. & study/scholarship \\
\hline Chiara & $\mathrm{F}$ & Italy & U.S. & study/scholarship \\
\hline Malik & M & Iraq & U.S. & refugee/American dream \\
\hline Maxime & $\mathrm{F}$ & Chad & U.S. & study/Fulbright \\
\hline Li Ming & $\mathrm{F}$ & China & U.S. & not satisfied with pedagogy at her university \\
\hline Ekaterina & $\mathrm{F}$ & Russia & U.S. & $\begin{array}{l}\text { to study, fell in love with country after short summer } \\
\text { work visit }\end{array}$ \\
\hline Eduardo & M & El Salvador & U.S. & freedom from family, experience something different \\
\hline Akari & $\mathrm{F}$ & Japan & U.S. & improve English for work \\
\hline Mei & $\mathrm{F}$ & China & U.S. & to study in graduate school \\
\hline Rosa Maria & $\mathrm{F}$ & Colombia & Spain, then U.S. & work, then family \\
\hline Amadi & M & Nigeria & South Africa & in search of "greener pastures" for job, study \\
\hline Jacoline & $\mathrm{F}$ & Zimbabwe & South Africa & $\begin{array}{l}\text { in response to South Africa's demand for math and } \\
\text { science teachers, in search of better quality of life }\end{array}$ \\
\hline Osakwe & $\mathrm{M}$ & Nigeria & South Africa & to study \\
\hline Tanisha & $\mathrm{F}$ & Nigeria & South Africa & to join husband \\
\hline Urbi & $\mathrm{F}$ & Nigeria & South Africa & husband wanted to further his education \\
\hline Mbeke & $\mathrm{F}$ & Nigeria & South Africa & to join husband \\
\hline Cédric & $\mathrm{M}$ & Cameroon & South Africa & for higher theological education \\
\hline Sonia & $\mathrm{F}$ & Cameroon & South Africa & wanted quality education to better her life and future \\
\hline Maiba & $\mathrm{F}$ & Zimbabwe & South Africa & to join husband who was working there \\
\hline Innya & $\mathrm{F}$ & Nigeria & South Africa & to further her studies \\
\hline
\end{tabular}

consent when students agreed to be interviewed. Interviews ranged from 15 minutes to an hour and consisted of the following open-ended questions: (1) Why did you come to South Africa/the United States? (2) Tell me the story of your departure from your country and the journey to South Africa/the United States; (3) Tell me a memorable experience you have had after arriving in South Africa/ the United States; (4) Describe your life now. Has it changed? If so, how? and (5) What would you like to tell the world about the experience of human migration? Is there anything that you would like people to know? These questions purposefully focus on the migration experience and not on classroom experience, as we must first understand the former in order to understand the latter.

\section{Data analysis}

Interview data was first uploaded to the AntConc 3.2 qualitative software analysis program in order to conduct a comprehensive analysis of metaphors relating to the immigration/adjustment process. In the 
first iteration, the authors conducted multiple analyses of the text, first manually (through word highlighting and coding features), color coding, and searching for potential metaphors in the text. Once preliminary metaphors were coded, tables were made to track potential metaphor sources. Then with AntConc, the text was searched again to ensure that all tokens of each metaphor type were found. After this phase of analysis, the authors created new tables that tabulated the number for each type of metaphor, and member checking occurred to make sure that all authors agreed on the metaphor categories. Next, each metaphor was searched for possible other collocations and those terms were searched again in AntConc to make sure no metaphors were neglected. The final phase in the metaphor analysis consisted of tabulating all metaphors and determining dominant, secondary, and occasional metaphors (as per Santa Ana, 2002) to understand the prevalence of certain metaphors among participant interviews and across differing sociopolitical, economic, and cultural contexts. After the metaphor analysis was complete, the authors coded the data once again for metonymies and deixis ${ }^{4}$ relating to identity negotiation. Results will be discussed in the identity negotiation section.

\section{Findings}

\section{Metaphor analysis}

Metaphor analysis revealed intriguing perceptions of the migration experience by the participants that can be useful in understanding the participants' identity frames. Table 2 lists the dominant, secondary, and occasional metaphors found in the data from participants in both countries (as modeled in Santa Ana, 2002).

With regard to the total number of metaphors found, the lower number for the South African data can be easily explained by looking at the total word counts (tokens). Although interviews in both countries utilized the same interview protocol, it is clear from the large difference in number of tokens that the U.S. interviews yielded much more data and therefore the difference in metaphor tokens can be accounted for as such. ${ }^{5}$ With regard to the types of metaphors found, striking similarities appeared between conceptualizations of migration by participants in both countries, despite different historical, 
Table 2. Metaphors With target IMMIGRATION: United States and South Africa.

\begin{tabular}{|c|c|c|c|c|}
\hline Type & Source domain & United States & Source domain & South Africa \\
\hline \multirow[t]{3}{*}{ Dominant } & $\begin{array}{l}\text { WAR } \\
\text { (e.g., struggle, fight weak position) }\end{array}$ & $\begin{array}{c}85 \\
(32.3 \%)\end{array}$ & $\begin{array}{l}\text { DANGEROUS JOURNEY } \\
\text { (e.g., navigating, led the way) }\end{array}$ & $\begin{array}{c}38 \\
(31.0 \%)\end{array}$ \\
\hline & DANGEROUS JOURNEY & 56 & WAR & 35 \\
\hline & (e.g., abandonment, different path) & $(21.3 \%)$ & (struggling, attacked) & $(28.25 \%)$ \\
\hline \multirow[t]{2}{*}{ Secondary } & VIOLENT FORCE & 24 & VIOLENT FORCE & 7 \\
\hline & (e.g., shocked, pushed) & $(9.5 \%)$ & (e.g., pressing, feel the impact) & $(6 \%)$ \\
\hline Occasional & $\begin{array}{l}\text { DOOR, PUZZLE, BEING AT EASE, } \\
\text { CULTIVATION, SECRET CODE, } \\
\text { COMPETITION, EDUCATION }\end{array}$ & $\begin{array}{c}97 \\
(37.0 \%)\end{array}$ & $\begin{array}{l}\text { DOOR, PUZZLE, BEING AT EASE, } \\
\text { CULTIVATION, SECRET CODE, } \\
\text { COMPETITION, EDUCATION }\end{array}$ & $\begin{array}{c}44 \\
(35.5 \%)\end{array}$ \\
\hline \multirow[t]{2}{*}{ Total Metaphors } & & 263 & & 124 \\
\hline & & $(100 \%)$ & & $(100 \%)$ \\
\hline Total Tokens & & 48,252 & & 14,364 \\
\hline
\end{tabular}

economic, and cultural contexts of both countries of origin and destination countries of participants. The two dominant metaphors found in the data were IMMIGRATION IS A WAR and A JOURNEY. These two metaphors reveal much about how IS perceive the difficult process of adapting to a new country. In the case of IMMIGRATION IS A WAR, the characteristics of war are mapped onto the adjustment/immigration process, equating adaptation with an epic battle in which the migrants are the soldiers and the advisors/mentors/professors are their commanders in their "battle" for survival. The battlefield becomes the classroom, and students must bring their weapons (i.e., language skills, education) to fight their opponents, who are members of the receiving society and who do not want them there. They also must "fight" against nostalgia and the longing to be back in their countries of birth. In the process of doing "battle," the IS must use the proper strategies, such as trying to make friends with people from the receiving country and using their networks of peers to gain information about how the system works. In the end, there is victory (acceptance into society, life improvement) or defeat (no improvement, life is harder than before, possible return). In this narrative, the focus is on the struggle and hardship involved in this often-painful process.

In the second dominant metaphor, IMMIGRATION takes on the characteristics of a JOURNEY in which the IS are the travelers with 
the destination being integration and acceptance into society and, in many cases, life improvement. On their journey, these travelers often have a travel guide (their mentor or advisor) to help guide them as they encounter the numerous obstacles (e.g., discrimination, lack of jobs, language) in their way. They must also make decisions about their path (e.g., which classes to take, whether to stay or return home, which strategies to use to fit in) along the way. In this conceptualization of migration, the emphasis is on travel to a destination, which is a better life. In essence, this metaphor is a submetaphor of LIFE IS A JOURNEY with the focal point being the migration experience. The following examples demonstrate how these conceptual metaphors were realized linguistically during the interviews. In the below first excerpt and example of IMMIGRATION IS A WAR, Akari talks about how language was used as a weapon against her in the United States and how her own English language ability did not provide her with the necessary tools to stand up to her supervisor:

Akari: But then I don't have this, you know, language ability to fight back. And also culturally, you know, I'm not sup- it's re-I feel really uncomfortable to, you know, fight against my, you know boss, coordinator. So I feel like I'm always in this weak position, that [pause] that my, where my supervisor always have-

First author: What do you think made them put you in that weak position? Because you're a student, or-

Akari: No, I think it's basically they use my language ability and also cultural background, she knows that I don't really fight against her. . .she speak like, you know, like a machine gun dudududududu, and I cannot really have room to you know, say my point.

Akari's comparison of her supervisor's language to a machine gun is particularly poignant in understanding the way that people often perceive speech when they have difficulty understanding it (dudududurapid sounds that do not have meaning), but they also reveal feelings of weakness, victimhood, and loss of control that are often felt by newcomers that must learn a new language. This conceptualization of the process as a WAR was common in the data (as shown by the fact that 
it was a dominant metaphor) and exposes the difficulty and traumatic experience that migration often is, despite the fact that all of the immigrants interviewed were highly educated and varied greatly in social, economic, and cultural backgrounds.

In the case of the other dominant metaphor, IMMIGRATION IS A JOURNEY, numerous examples existed in which the process of immigration and adaptation was seen as a type of quest in which there was a "starting point, endpoint, route to be traversed (possibly with impediments) and a sense of directedness" on the part of the traveler to follow the path to the end (Santa Ana, 2002, pp. 176-177). These metaphors were largely positive and reflect a conceptualization of immigration as another journey in life. In the following excerpts, Ekaterina describes the beginning of her journey to the United States and her future plans, while Chiara describes the value of the immigration experience:

Ekaterina: Mostly, especially in the beginning, it was that feeling being on my own when I didn't have anybody who could help me or either spend the time that I spent all my own. . . . Now, everyday I feel I am so blessed. And of course I still have my goal to graduate, hopefully this December, but I think my next step is really have a family, and you know we will go from there.

Chiara: It can be hard, but at the same time it, it's worth it, because we really are enriched in the end.

While these examples describe the immigration process as part of life's journey, the following examples highlight the traumatic nature of the experience as it is conceived of as a violent force:

Mei: See, at the beginning I was re-[pause] I was pushing away everything. I was [pause] fa- [pause] how do you say, romanticizing Chendou, or my home, and uh, so I was resentful of a lot of things at the beginning.

Tanisha: Because people who came and weren't very prepared they meet some of these things. Like some of them go to jail, some of them go into drugs and some other things. They can't take the shock.

First Author: Would you do the same experience, would you move to another country? 
Chiara: Oh, oh sure! Yes. Maybe I would try to prepare myself a little more by the difficulties of, of being in Capital City because it's not as easy as being in other places [pause] so yeah maybe also that helps, to try to know a little bit in advance so that the shock is not that [pause] violent.

Besides the dominant and secondary metaphors, numerous other occasional metaphors existed in the data that illustrated the complexity, variability, and dynamic nature of how migration is experienced and conceived and the ways in which IS view the adaptation process. Interestingly, many of these metaphors pointed to positive perceptions of the experience. The following examples demonstrate the positive view of immigration as cultivation, which maps the characteristics of a plant onto IS. In this frame, the student is the seed, and the immigration experience is the fertile, temperate environment needed for the seed to sprout and reach its full potential (Santa Ana, 2002) as a student and future teacher. Li Ming illustrates this metaphor when she notes that immigration "helps me grow as a better person and as [sic] better teacher and educator." In addition, Ana reveals her perception of immigration as a form of personal cultivation when she adds, "I think my life is [pause] how do you say? [pause] más nutritiva [more nourishing/enriching]." We will now turn our attention to the ways in which other elements of the linguistic analysis support CIT and reveal identity negotiation on the part of the participants.

\section{Identity negotiation}

Building on the metaphor analysis, which allowed us to understand IS perceptions of the immigrant experience, we now examine the use of metonymy and deixis which can also be helpful in understanding the identity development and change that occurs when IS are adjusting to life in a new country and school. Much insight into identity negotiation was found in the data, but we will focus on examples that support CIT, positioning IS in inclusive and exclusive ways. The next excerpt illustrates Chiara's personal identity as a cosmopolitan person, despite the fact that she finds many people who want to identify her only as an Italian. Here she describes how she sees herself and her strategy for integrating into American society by taking the best of each of the cultures she is familiar with: 
Chiara: But, so I'm trying to think of myself more, you know, every single day, uh, as a cosmopolitan person whose, you know, I got to live in Russia, I got to live in America, or I got to live in Italy for many, many years, and so I can combine all these, um, experiences and try to use them all, and also, try maybe to detach myself a little bit from, um, being solely and merely an Italian but try to integrate what's the best that I can have from the American. . .

The next example demonstrates Rosa Maria's experience with her new blurred identity, and her sense of liminality in not belonging fully to any culture or people.

Rosa Maria: Your identity blurs. So I feel right now that I am like in a limbo. So, I, you know, when people ask me, "Where are you from?” Of course I say, "I'm Colombian,” right? And I- and Iand I have Colombia in my heart [pause]. But then when I see them talk to people [pause] it's like we don't- like I don't fit anymore- the way that I used to fit. And that- and that is hurtful. That- that's hurtful. Um, because I don't feel either here that I'm the perfect fit and I'm not the perfect fit in Spain either. So, I feel like I'm [pause] like part of my- like- Part of me is from Spain- part from is from Colombia first, part from me is from Spain, part of me is from the United States.

The expression in a limbo refers to the region of afterlife some religions believe is designated for souls that go neither to heaven nor hell and reflects the metaphorical comparison of being in an intermediate state of waiting that compares immigration to a type of death or rebirth. This perspective of immigration and cultural adjustment as being in limbo, reflects the difficult and often painful process (e.g., hurtful) in which identity is negotiated for IS as they work to fit in, be good students, and at the same time maintain ties to their past. Another interesting metaphor revealed in this excerpt is how Rosa Maria refers to herself in terms of being divided into parts or pieces. This conceptualization can be traced back to PART-WHOLE image-schemas ${ }^{6}$ of our bodily experiences as being whole bodies with parts (e.g., fingers, hands). This idea of parts is then expanded and taken to a metaphorical level because the parts she is speaking of are not physical 
body parts, but cultural and linguistic pieces that can be separated, fit well (or not), and have different origins. Thus the metaphor becomes IMMIGRATION IS A PUZZLE, and its entailment, CULTURAL AND LINGUISTIC IDENTITY ARE PIECES. Moving the pieces around and seeing how they fit together best are all part of the adjustment process for Rosa Maria and other participants. The next example implicitly describes Malik's enacted identity as experienced in his attempts to communicate with others and as he dispels advice he would give to other refugees or migrants. Here the use of deixis plays an important role in establishing Malik's identity in relation to other Iraqi immigrants:

Yeah. Uh, so, there's a question about my advice-what I recommend for the new refugees. What I recommend them is to know the culture and know the language, and to fully integrate yourself and your family in the community. Most of the refugees and the Iraqis when they came to America, they don't wanna associate with Americans. They only associate with their people, withwith the Iraqis or with other people. But you will not learn anything, you will not learn English [pause]. They don't care now if, if we have a shooting in one of the schools, they don't care, but-because they don't consider themselves as American.

In the above excerpt, strategic use of the pronouns they and them serves to disassociate Malik from other Iraqi refugees that take a different approach and do not easily integrate into society. According to Petersoo (2007), understanding the use of deictic expressions can be enlightening, and inclusive and exclusive pronouns (such as they and we) can be most revealing of the boundaries that separate Self and Other. By repeatedly referring to (Iraqi) refugees as they, and including himself in the we (e.g., "if we have a shooting in one of the schools") Malik successfully enacts his own identity as a person interested in integrating and being accepted into American society by distancing himself from those who do not. He also speaks directly to other refugees in the United States by using the second person you when dispensing advice in an imaginary conversation with others in similar situations.

Another example of the use of deictic expressions in identity negotiation can be seen in Urbi's comment that demonstrates her perceptions of the communal identity ascribed to her by South Africans. 
Through use of pronouns that strongly delineate the Us versus Them dichotomy she describes her attempts to get a job in South Africa:

Urbi: But you feel ostracized that you are not part of the system because the way the system treats you is that they don't want you. Whether you are qualified or you are not qualified they don't want you, it doesn't matter. You know I was in the principal's office. He called the department while I was seated and said, "I need a teacher in my school desperately now and I have one who can teach the subject and she is a foreigner [pause].” And he did everything he could immediately. But I felt that they just deceived him into taking action. He went there himself. He went to the district office. By the end of the day he came back to me and said, "What I can summarily say to you [pause] is that you are not wanted. They don't want you."

Several elements are worth noting in the above example such as the principal's use of the metonymy foreigner and the repetitive they versus you, where you is referring to herself (Urbi) and others like her. As noted in the literature review, these perceived identity gaps (between how she is seen as a foreigner and her own identity as a qualified teacher) can be detrimental to successful integration into the receiving society and reflect a "social mirror" that does not match how the participant sees herself, creating inner conflict. In this case, Urbi's personal identity as a qualified professional conflicts with how she is seen as an outsider-foreigner and an undesirable. The excerpt also hints at the participants' knowledge of the history of Black African immigrants in South Africa and the somewhat recent backlash felt by many Black South Africans who feel that Black immigrants are taking their jobs. ${ }^{7}$ Here Amadi comments on what it is like to be a foreigner in South Africa.

Amadi: It is not easy to be a foreigner in another man's country especially when the recipient country is hostile towards foreigners.

Amadi's use of the metonymy another man's country brings to light his own identity and the perception that he still does not consider South 
Africa to be his country and that it belongs to another man. In addition, his view of South Africans as hostile towards foreigners reveals his perceptions of his ascribed identity by South Africans only as a foreign, an outsider, whereas he views himself as a Nigerian. In the next example, Ana talks about how before going to the United States, she never thought about her ethnicity (she refers to it as her race in the excerpt):

Ana: And [pause] this is one part. On the professional part, I think I [pause] at the first time in my life I have to think, thought more about race, about my race.

$\mathrm{R}$ : Whereas you never felt that in Chile?

Ana: Yes. (. . .) For instance, some people from here think, okay, you are Latino, you are a Mexican, and they have very strong stereotypes about Mexican people, like, okay, you are an illegal, and you are not smart because you are not a native speaker, you're a [pause] you don't speak English very well, so you have a strong accent...

As a Latina familiar with the discriminatory environment Latinos have been exposed to in the United States, Ana immediately noticed the reaction of people to her when they looked at her and heard her accent. However, as Ana points out in the following excerpt, once they found out she was from Chile, she realized that there was a hierarchy with respect to how Latinos are viewed in the United States:

Ana: Yes, you know [pause] I, they have a hierarchy, I think [pause] sometimes. For instance, okay, where are you from? I'm from Chile. Ahhh, okay. You, you get more points. (laughs)

R: You get more points on the scale.

Ana: What are you doing here? I'm studying. Aaah [pause] what are you studying? More points.

Here Ana notices that being a graduate student, coming from Chile (as supposed to Mexico) and being highly educated produces different reactions from Americans, which made her realize and struggle with the stereotypes many Americans have about Mexicans. These stereotypes and attitudes toward Mexicans make her very uncomfortable not only because people often lump all Latinos into one category and thus 
extend these attitudes in her direction, but also because many of her friends in the United States are Mexican (Interview, September 2013). Ana also noted (in the first excerpt) the reactions of Americans to her accent and nonnative-like English. Below, Akari also relates her appearance, accent, and ability to speak English as closely connected to her ability to fit in and integrate into society:

Akari: That's another thing [pause] here, Caucasian-looking, an, you might get lots of attention, and um-

First Author: So you think your appearance-

Akari: Partially my appearance, and also my probably speaking [pause] I feel like I'm a lot better off if I could speak like Americans, you know. . .

Interestingly, 6 out of 10 participants in the United States and 5 out of 10 of those in South Africa mentioned being recognized (and often treated differently) because of their accent or inability to speak the local language. Thus, although Akari and others often desperately want to fit in, they are often not able to because of the language(s) they do not speak or their accent. Earlier we mentioned the concepts of strong identity security and inclusive identity orientation, which according to Kim (2009) are important in becoming interculturally competent in the receiving country. In the following example, Amadi demonstrates his national pride and strong identity security, despite the fact that he knows he is different and is often viewed negatively in South Africa because of it:

Amadi: Of course I am a Nigerian, that is my identity and I am proud of it. My name, my language, my accent, personal appearance and ways of life differentiates me from the rest and I have to live with that.

Next, Innya demonstrates her increasingly inclusive identity orientation and ability to integrate into South African society by turning possible conflicts into jokes and using her sense of humor to win over the people:

Innya: So it's not as if [pause] at first instance people don't approach me with xenophobia. It is when I introduce myself. When I say I 
am a Nigerian. Then they now say uhm you foreigners [pause] I can't say I experienced xenophobia as such. Because even if I am in a taxi, a lot of them are speaking and they expect me to speak a South African language and I don't speak and they discover that I maybe a Kwerekwere as they call them. They never called me a Kwerekwere before, but even if they do something like that I'll just turn it into a joke. I'll just say, "You, are you talking to me?" You know that kind of a joke and at the end of the day we all become friends. So that is it.

Another example of the development of inclusive identity orientation can be seen below when Tanisha is asked how life has changed for her. She replies:

Tanisha: Hey (laughs) Ja. it changed because I learnt the culture of the land. How people relate with one another. I had to sit down and study the people I'm dealing with, understand who they are, how they reason, how they talk. Remember from where I am coming it is a different thing. So if I don't understand the culture of the people. . you are dealing with the Zulus, they are a different culture. The Xhosas, the Vendas, the Tsongas . . you understand? The Sothos. I have to learn the different people and what they represent. You understand? So I related to them from that angle ... My life has changed. My pattern of doing things has also changed.

Tanisha's comment reveals how she has learned to adapt to life in South Africa, which has resulted in the formation of positive relationships with other South Africans. Her strategy of studying the people (note the metaphor: IMMIGRATION IS EDUCATION) and learning the different cultural nuances has rendered her more confident in her social relations.

\section{Conclusion}

Through linguistic analysis of interviews with IS conducted in the United States and South Africa, the present paper has demonstrated the diverse and dynamic nature of perceptions about the migration 
experience in both countries. Remarkable similarities were found in how IS perceive the immigration and adaptation experience despite vast differences in historical, social, cultural, and economic contexts of the IS (and reasons for migrating) and their countries of origin/destination countries. Dominant metaphors of IMMIGRATION IS A JOURNEY or WAR and the secondary metaphor IMMIGRATION IS A VIOLENT FORCE underscore the paradoxical nature of the at-once exciting and traumatic enterprise that is human migration. Interestingly, although many of the participants in South Africa appeared to have more financial difficulties and experienced more outward discrimination than many of the interviewees in the United States, metaphors revealed that the dominant perceptions of the experience for participants in both countries were still that of difficulty, struggle, and shock, but also that of joy, hope, and personal growth (such as that seen in the CULTIVATION metaphor). In regard to identity, numerous examples were found in the data that demonstrated how personal, enacted, and relational/communal identities often clash, leaving gaps that result in disappointment or discouragement. Analysis of deixis revealed a commonly perceived Us versus Them mentality whereby ascribed identities did not always permit the IS to integrate (such as in the case of Amadi) and language, for many of the participants, (whether it was the ability to speak the local languages in South Africa or lack of English proficiency or having an accent in the United States) served as an identity marker that made integration and adaptation often difficult. Yet in spite of all this adversity, IS overall showed an incredible resilience and continual, constant development of intercultural competence and metacognitive awareness of strategies that allowed them to integrate and be successful and to take pride in what makes them different.

Implications of this study for educators in higher education are multifarious and include the need for educators to provide more support and information for students before they come to study, especially when they first arrive and must navigate a new system that includes the culture of school and of the larger society and the sometimes hostile reception they receive. In addition, educators would do well to remember Akari's metaphorical conception of speech as a machine gun and adjust their own speech rate and use of repetition in accordance with the students' needs. Furthermore, teachers need to be aware that attitudes toward the students and their ethnicity, race, 
or nationality can have an impact on the success of the students, and therefore, instructors should not only make sure they are not communicating negative attitudes towards their students but also make an effort to facilitate positive attitudes of other students toward IS in their classroom. One way to do this is to engage students in activities that allow students to connect with each other while working towards common course goals. In this way learners can "feel the presence of others in a way that honors their transcendence of categories (i.e. gender, ethnicity, race)" (Blumenfeld-Jones, 2012, p. 106). Educators in both the United States and South Africa also need to be aware of the traumatic experiences these students often undergo, despite the fact that they are highly educated.

Findings from this paper demonstrate the incredible variety of reasons why IS come to study, types of experiences they undergo, and strategies they use to integrate. Understanding this variety is essential to being able to help these students, and educators must make the effort to get to know these students better so that they can retain them and benefit from the knowledge, intercultural competence, innovation, and professionalism that they bring to their receiving countries. Finally, we must never assume that because these students are highly educated, migration is not a daunting experience for them or that they do not experience discrimination or do not have difficulty adjusting or do have difficulty. We must always remember that these students are individuals with unique backgrounds but at the same time we must realize as Ekaterina so wisely stated at the end of her interview, despite everything, "It's still difficult to be different."

Acknowledgments The authors would like to thank all the participants for sharing their stories with us. In addition, we would like to thank Matsie Agnes Mohale for her contribution in conducting interviews for this project. Finally, the authors would like to thank the reviewers for their thoughtful comments and insights, which we feel have greatly ameliorated the paper.

Notes

1. While one of the criteria for participants was that they planned to stay in their receiving countries, the authors recognize that transnational migration is a worldwide dynamic phenomenon. Thus, it is likely that some of the participants' plans may have changed since the time of their interview. 
2. Cognitive linguistics is a powerful approach to the study of language that focuses on conceptual systems and meaning construction (Hart, 2010).

3. Note that when using the target domain IMMIGRATION, the authors include the entire process of immigration, including the travel from receiving country to destination country and the adjustment period afterwards.

4. Deixis refers to pronouns or other words that are used for purposes of positioning.

5. Reasons for the longer U.S. interviews can be attributed to various factors, such as lack of time constraints on the part of participants, familiarity with researchers, willingness to speak about the experience openly, etc.

6. Image-schemas are recurring patterns of our perceptual interactions and motor programs that give coherence to our experiences (Kövecses, 2006).

7. Matsinhe (2011) describes this backlash as a "violent aversion towards African foreign nationals" that represents "scapegoating" and the externalization of historical internal repression (p. 310), which culminated in xenophobic attacks in 2008 (Coplan, 2008; Hassim, Kupe, \& Worby, 2008). These attacks were directed towards Black immigrants (mostly the poorer and more vulnerable marginalized of society) by their Black South African counterparts (Vandeyar, 2012).

\section{References}

Benczes, R. (2011). Putting the notion of "domain" back in metonymy: Evidence from compounds. In R. Benczes, R. A. Barcelona, \& F. J. Ruiz de Mendoza Ibáñez (Eds.), Defining metonymy in cognitive linguistics: Toward a consensus view (pp. 197-215). Amsterdam, Netherlands: John Benjamins. doi:10.1075/ hcp.28.11ben

Berry, J. W. (2003). Conceptual approaches to acculturation. In K. M. Chin, P. Balls Organista, \& G. Marin (Eds.), Acculturation: Advances in theory, measurement, and applied research (pp. 17-38). Washington, DC: American Psychological Association. doi:10.1037/10472-004

Blumenfeld-Jones, D. (2012). Curriculum and aesthetic life: Hermeneutics, body, democracy, and ethics in curriculum theory and practice. New York, NY: Peter Lang.

Bresnahan, M. J., \& Kim, M. S. (1993). Predictors of receptivity and resistance toward international teaching assistants. Journal of Asian Pacific Communication, 4, 3-14.

Chan, E. J. (2004). Narratives of ethnic identity: Experiences of first-generation Chinese Canadian students (Doctoral dissertation, University of Toronto).

Cisneros, J. D. (2008). Contaminated communities: The metaphor of "immigrant as pollutant" in media representations of immigration. Rhetoric and Public Affairs, 11, 569-601. doi:10.1353/rap.0.0068

Coplan, D. (2008). Crossing borders. In S. Hassim, T. Kupe, \& E. Worby (Eds.), Go home or die here: Violence, xenophobia and the reinvention of difference in South Africa (pp. 119-131). Johannesburg, South Africa: Wits University Press. 
Copland, F., \& Garton, S. (2011). "I felt that I do live in the UK now": International students' self-reports of their English language speaking experiences on a presessional programme. Language and Education, 25, 241-255. doi:10.1080/095 00782.2011 .566617

Dion, K. K. (2006). On the development of identity: Perspectives from immigrant families. In R. Mahalingham (Ed.), Cultural psychology of immigrants (pp. 299-314). Mahwah, NJ: Lawrence Erlbaum.

Dirven, R. (2002). Metonymy and metaphor: Different mental strategies of conceptualization. In R. Dirven \& R. Porings (Eds.), Metaphor and metonymy in comparison and contrast (pp. 75-111). Berlin, Germany: Mouton de Gruyter.

Fitch, F., \& Morgan, S. E. (2003). "Not a lick of English": Constructing the ITA identity through student narratives. Communication Education, 52(3-4), 297310. doi:10.1080/0363452032000156262

Gibbs, R. W., Jr. (1999). Speaking and thinking with metonymy. In K. U. Panther \& G. Radden (Eds.), Metonymy in language and thought (pp. 61-76). Amsterdam, Netherlands: John Benjamins.

Guo, S., \& Chase, M. (2011). Internationalisation of higher education: Integrating international students into Canadian academic environment. Teaching in Higher Education, 16, 305-318. doi:10.1080/13562517.2010.546524

Hart, C. (2010). Critical discourse analysis and cognitive science: New perspectives on immigration discourse. Hertfordshire, UK: Palgrave Macmillan.

Hart, C. (2011). Moving beyond metaphor in the cognitive linguistic approach to CDA: Construal operations in immigration discourse. In C. Hart (Ed.), Critical discourse studies in context and cognition (pp. 71-92). Amsterdam, Netherlands: John Benjamins.

Hassim, S., Kupe, T., \& Worby, E. (Eds.). (2008). Go home or die here: Violence, xenophobia and the reinvention of difference in South Africa. Johannesburg, South Africa: Wits University Press.

Hecht, M., Jackson, R. L., II, Lindsley, S., Strauss, S., \& Johnson, K. E. (2001). A layered approach to ethnicity: Language and communication. In W. P. Robinson \& H. Giles (Eds.), The new handbook of language and social psychology (pp. 429-449). New York, NY: John Wiley.

Hecht, M. L., Jackson, R. L., \& Ribeau, S. A. (2004). African American communication: Exploring identity and culture. Mahwah, NJ: Erlbaum.

Hecht, M. L., Warren, J. R., Jung, E., \& Krieger, J. L. (2004). The communication theory of identity: Development, theoretical perspective, and future directions. In W. B. Gudykunst (Ed.), Theorizing about intercultural communication (pp. 257-278). London, United Kingdom: Sage.

Hsieh, M. H. (2006). Identity development of East Asian female international students with implications for second language higher education. Education, 127(1), 3-15.

Jakobson, R. (1956). Two aspects of language and two types of aphasic disturbances. Republished in 1971, Selected Writings II. (pp. 239-259). The Hague: Mouton. 
Kim, Y. (2009). The identity factor in intercultural competence. In D. Deardorff (Ed.), The Sage handbook of intercultural competence (pp. 53-65). Thousand Oaks, CA: Sage. doi:10.4135/9781452281988.n28

Kim, E., \& Egan, T. (2010). Establishing a formal cross-cultural mentoring organization and program: A case study of international student mentor association in a higher education context. Journal of European Industrial Training, 35, 89-105. doi:10.1108/03090591111095754

Kövecses, Z. (2006). Language, mind, and culture: A practical introduction. Oxford, United Kingdom: Oxford University Press.

Lakoff, G., \& Johnson, M. (1980). Metaphors we live by. Chicago, IL: Chicago University Press.

Matsinhe, D. (2011). Africa's fear of itself: The ideology of Makwerekwere in South Africa. Third World Quarterly, 32 (2), 292-313. doi:10.1080/01436597.2011.56 0470

Murrell, P. C. (1999). Class and race in negotiating identity. In A. Garrod, J. Ward, T. Robinson, \& R. Kilkenny (Eds.), Souls looking back: Life stories of growing up Black (pp. 3-14). New York, NY: Routledge.

Panther, K. U., \& Thornburg, L. L. (2003). Introduction: On the nature of conceptual metonymy. In K. U. Panther \& L. L. Thornburg (Eds.), Metonymy and pragmatic inferencing (pp. 1-22). Philadelphia, PA: John Benjamins.

Petersoo, P. (2007). What does "we" mean? National deixis in the media. Journal of Language and Politics, 6, 419-436. doi:10.1075/jlp.6.3.08pet

Rubin, D. L. (1992). Nonlanguage factors affecting undergraduates' judgments of nonnative English-speaking teaching assistants. Research in Higher Education, 33, 511-531. doi:10.1007/bfoog73770

Rubin, D. L., \& Smith, K. A. (1990). Effects of accent, ethnicity, and lecture topic on undergraduates' perceptions of nonnative English-speaking teaching assistants. International Journal of Intercultural Relations, 14, 337-353. doi:10.1016/0147-1767(90)90019-s

Ruiz de Mendoza Ibáñez, F., \& Diez Velasco, O. (2002). Patterns of conceptual interaction. In R. Dirven \& R. Pörings (Eds.), Metaphor in comparison and contrast (pp. 489-532). Berlin, Germany: Mouton de Gruyter.

Ruiz de Mendoza Ibáñez, F., \& Perez Hernández, L. (2003). Cognitive operations and pragmatic implication. In K. U. Panther \& L. L. Thornburg (Eds.), Metonymy and pragmatic inferencing (pp. 23-50). Philadelphia, PA: John Benjamins.

Santa Ana, O. (1999). "Like an animal I was treated": Anti-immigrant metaphor in US public discourse. Discourse \& Society, 10, 191-224. doi:10.1177/095792659 9010002004

Santa Ana, O. (2002). Brown tide rising: Metaphors of Latinos in contemporary American public discourse. Austin: University of Texas Press.

Suárez-Orozco, C. (2004). Formulating identity in a globalized world. In M. M. Suárez-Orozco \& D. B. Qin-Hilliard (Eds.), Globalization, culture and education in the new millennium (pp. 173-202). Los Angeles: University of California Press. 
Suárez-Orozco, M. M. (2000). Identities under siege: Immigration stress and social mirroring among the children of immigrants. In A. C. G. Robben \& M. M. Suárez-Orozco (Eds.), Cultures under siege: Collective violence and trauma

(pp. 285-297). New York, NY: Cambridge University Press. Suárez-Orozco, C., \& Suárez-Orozco, M. (1995). Transformations: Migration, family life and achievement motivation among Latino adolescents. Palo Alto, CA: Stanford University Press.

Suárez-Orozco, C., \& Suárez-Orozco, M. M. (2001). Children of immigration. Cambridge, MA: Harvard University Press.

Taylor, C. (1994). Multiculturalism: Examining the politics of recognition. Princeton, NJ: Princeton University Press.

Vandeyar, S. (2012). Immigrant students' shifting identifications in South African schools. International Journal of Educational Development, 32, 232-240. doi:10.1016/j.ijedudev.2011.03.006

Wadsworth, B. C., Hecht, M. L., \& Jung, E. (2008). The role of identity gaps, discrimination, and acculturation in international students' educational satisfaction in American classrooms. Communication Education, 57(1), 64-87. doi:10.1080/03634520701668407

Williams, C. T., \& Johnson, L. R. (2011).Why can't we be friends? Multicultural attitudes and friendships with international students. International Journal of Intercultural Relations, 35(1), 41-48. doi:10.1016/j.ijintrel.2010.11.001 